\title{
Excavating Theogonies
}

Where do babies come from? Archaeologists do not need to dig around for an answer to this question as they attempt to understand and explain the empirical data uncovered at sites in the Neolithic or elsewhere. ${ }^{1}$ They certainly need to search for plausible hypotheses to illuminate the vital kinship structures, pregnancy rituals, birthing practices, and neonatal health care policies of any specific community. However, if the community was composed of anatomically modern Homo sapiens, archaeologists can appropriately assume that infants appeared within the population as a result of the same basic procedures that produce them today, when ... well, you know.

Where do gods come from? In this chapter I will argue that archaeologists (as well as other scientists, philosophers, and theologians) can now also appropriately assume that the reproduction of supernatural agents in ancient civilizations occurred in much the same way that it does today. Although we have known where babies come from for several millennia, only within the last few decades have we come to understand more fully why gods appear (and are cared for) in human populations. As with the process of bearing children, one finds an astonishing variety of ways of ritually surrounding and socially manipulating the process of bearing supernatural agents. Beliefs about and behaviors toward the latter are regulated and transmitted differently in the major religious traditions that were forged within complex literate states during the axial age and now dominate the global landscape. Nevertheless, all members of our species share a phylogenetic heritage that includes sets of cognitive and coalitional tendencies, whose interactions help to explain why gods are so easily born(e) in minds across cultures.

This is the first purpose of this chapter: to offer another brief reconstruction of some relevant theoretical advances in the bio-cultural study of religion, pointing to the convergence of insights from a variety of disciplines around the two conceptual attractors that I call theogonic mechanisms (anthropomorphic promiscuity and sociographic prudery). I demonstrate the potential illuminative power of these advances in relation to the empirical findings at

1 This chapter is an adapted version of "Excavating Theogonies: Anthropomorphic Promiscuity and Sociographic Prudery in the Neolithic and Now," originally published in Religion at Work in a Neolithic Society: Vital Matters, ed. Ian Hodder (Cambridge: Cambridge University Press, 2014).

(C) F. LERON SHULTS, 2018 | DOI 10.1163/9789004360952_004

This is an open access chapter distributed under the terms of the CC BY-NC-ND 4.o license. Shults - 9789004360952 
Çatalhöyük, a Neolithic archaeological site in southern Turkey. In the field of archaeology I am an amateur (in both senses of the word), and will not pretend to offer expert analyses of the data. And so this chapter has a second, more philosophical and perhaps even more daring, purpose: to explore some of the implications of the unearthing of these theogonic mechanisms for the shared global future of the human race, attending to the adaptive challenges and opportunities that must be faced today in light of our new understanding of the impact that bearing gods has on our mental and social well-being.

In an earlier analysis of the material, social, and spiritual entanglement at Çatalhöyük, I used the term "religion" in a broad sense to indicate the way in which humans symbolically engage what they take to be of ultimate value. ${ }^{2}$ In the current context, however, I am focusing more narrowly on a particular feature of human life that also appears across cultures: shared imaginative engagement with axiologically supernatural agents. In this sense, "religion" was entangled within and developed alongside all of the other vital matters that shaped human evolution. In the conclusion, I will emphasize the philosophical, psychological, and political significance of the unveiling of the mystery of god-bearing mechanisms, which, like Girard's scapegoat mechanism, only work well when they are hidden.

The bulk of the chapter is a conceptual excavation and reconstruction of ways in which some components of anthropomorphic promiscuity and sociographic prudery may have operated at Çatalhöyük. How was their imaginative interaction with supernatural agents (such as the spirits of ancestors and aurochs) vitally entangled with the material and social dimensions of their lives? To what extent were their production of food and artifacts and their regulation of communal property shaped by their perception of the causal power and social relevance of such agents? It seems to me that bulls, burials, and proprietary production were all mixed together at Çatalhöyük. The first step, however, is to provide another brief summary of the general conceptual framework that will guide my archaeological and philosophical observations.

\section{"Bearing Gods" in the Neolithic}

It should be clear enough that my use of the term bearing plays a double function, indicating the naturally evolved processes by which gods are born in human cognition (by the over-active detection of agency) and borne in human

2 Shults, "Spiritual Entanglement: Transforming Religious Symbols at Çatalhöyük" in Religion in the Emergence of Civilization, ed. Hodder (Cambridge University Press, 2010). 
culture (by the over-active protection of coalitions). Here I will continue using the term god as basically synonymous with supernatural agent; that is, a disembodied (dis-embodi-able, or at least ontologically confused) intentional force that is imagined to have some interest in and causal power over the members of a religious in-group. Despite - or because of - their ontologically confused status, these agents are believed to be capable of playing some kind of constitutive and/or regulative role in the social life of a particular human coalition. In this sense, the monotheistic idea of "God" also falls within this category, although it has distinctive features that need to be parsed out in other contexts for different reasons. ${ }^{3}$

My interest here is in uncovering some of the general mechanisms that condition all kinds of theogonies. I am using this latter term not in the narrow sense of popular literary accounts of the genesis of the gods, such as Hesiod's graphic portrayal of Cronos' swallowing of divine offspring and mutilation of titanic genitals, but more broadly as a way of referring to any narrative imaginative engagement that reinforces the detection and protection of a particular supernatural agent coalition.

Accepting the risk of blurring still other important distinctions within and across disciplines, I offer a heuristic model of the integration of these mechanisms, which is based on my reconstructive reading of recent empirical findings and theoretical reflections across a variety of fields including archaeology, cognitive science, evolutionary neurobiology, moral psychology, history, social anthropology, economics, and political science. As we have seen, and will see in more detail below, several trends within these and other disciplines converge in supporting the general hypothesis that gods are born(e) as a result of evolved human tendencies to over-detect agents in the natural environment and to over-protect coalitions in the social environment. These cognitive and cultural strategies contributed to the survival of hominid groups before, during, and after the Neolithic. The key question today is whether they are still healthy strategies for adapting in our rapidly changing, pluralistic environment. Are there other directions we could or should pursue?

The conceptual framework depicted in Figure 1 (see Chapter 1, page 3) can help clarify the options. The level of generality at which human tendencies are depicted on this grid does not allow us to capture all of the nuances within the various theories on offer within the many disciplines we will explore. However, it does capture precisely what is needed to accomplish the general purpose for which the framework has been constructed: clarifying the relation between

3 See, e.g., Shults, "The Problem of Good (and Evil): Arguing about Axiological Conditions in Science and Religion," and Chapters 6 and 7 below. 
two basic tendencies found among Homo sapiens, the integration of which leads to the reproduction of shared imaginative engagement with axiologically relevant supernatural agents. ${ }^{4}$

To review, the horizontal line represents a spectrum on which we can mark the tendency of persons to guess "human-like supernatural force" when confronted with ambiguous phenomena in the natural environment. The anthropomorphically promiscuous are always on the lookout, jumping at any opportunity to postulate such agents as causal explanations even - or especially - when these interpretations must appeal to disembodied intentionality. The anthropomorphically prudish, on the other hand, are suspicious about such appeals. They tend to reflect more carefully before giving into their intuitive desire to grab at explanations that refer to discarnate intentional entities.

The spectrum represented by the vertical line registers the extent to which a person inflexibly holds on to the modes of inscribing the social field favored by his or her religious in-group; i.e., to the proscriptions and prescriptions that regulate the evaluative practices and boundaries of the supernatural coalition(s) with which he or she primarily identifies. Sociographic prudes are strongly committed to the authorized social norms of their coalition, following and protecting them even at great cost to themselves. They are more likely to be suspicious of out-groups and to accept claims or demands that appeal to the supernatural authorities within their own coalition. The sociographic promiscuity of those at the other end of the spectrum, on the other hand, leads them to be more open to intercourse with out-groups about alternate normativities and to the pursuit of new modes of creative social inscription. Such persons are also less likely to accept restrictions or assertions that are based only or primarily on appeals to religious conventions.

Most human beings today are intuitively drawn toward anthropomorphic promiscuity and sociographic prudery, which are integrated in the lower left quadrant of Figure 1. Why? This is due, in part, to the inheritance of traits that were naturally selected (or by-products of other adaptations) that evolved in early ancestral environments in which survival advantage went to hominids

4 In the original version of this essay, I utilized definitions of anthropomorphic promiscuity and sociographic prudery that were broader than those stipulated in Chapter 1 above. In that earlier context, I did not tie those mechanisms so explicitly to religious biases. Instead, I referred to them as general cognitive and coalitional tendencies that could (and most often did) contribute to the detection of supernatural agents and the protection of supernatural coalitions. This was also my approach in the original versions of some of the other central chapters in this book. In each case, my revision of these essays has included altering these definitions so that they correspond to the hypotheses of theogonic reproduction theory as articulated in Chapter 1 . 
whose cognitive capacities enabled them to quickly detect relevant agents (such as predators, prey, protectors and partners) in the natural environment, and whose groups were adequately protected from the dissolution that could result from too many defectors and cheaters in the social environment.

A growing body of evidence suggests that the chance of survival would have been increased for those small groups of Homo sapiens who developed beliefs and rituals related to supernatural agents around 90-70,00o years ago. The integration of these mutually reinforcing theogonic mechanisms was highly adaptive. Sometime around 60,000 years ago it appears that some of these "god-bearing" groups left Africa, out-competing all other hominid species and spreading out across the Levant and into Europe and Asia. All living humans are the genetic offspring of these groups, and so share a suite of inherited traits that support the tendency to infer the presence of supernatural agents and prefer the social norms of their own supernatural coalitions. These naturally evolved traits were tweaked differently in various contexts, which led to the diversity of manifestations of religious life today. Supernatural agent conceptions are never immaculate; the particular features of our gods betray our religious family of origin.

The Neolithic is a particularly fertile time period for the purposes of excavating theogonies. Ancestor worship (or at least imaginative engagement with dead ancestors) had probably already emerged sometime between 50-30,00o years ago, and the upper Paleolithic was characterized by an explosion of innovations in tool-making, art, and burial elaboration. However, the Neolithic was "revolutionary" in many ways, most notably the shift toward sedentism and the domestication of plants and animals. For most of the 2oth century these developments were interpreted as the result of human responses to environmental changes and new modes of controlling material production and social organization, which in turn provided the conditions for the emergence of religion. Today, however, theoretical reflections on empirical research from a variety of disciplines have converged to suggest that imaginative engagement with supernatural agents played a generative and regulative role in the Neolithic "revolution."

Published at the turn of the century, Jacques Cauvin's The Birth of the Gods and the Origins of Agriculture 5 provides a illuminative example of this trend. He includes an assessment of Çatalhöyük within a broad overview and analysis of a variety of finds from earlier in the Natufian to the diffusion and eastern spread of agriculture later in the Neolithic. Cauvin argues that the key

5 Cauvin, The Birth of the Gods and the Origins of Agriculture, trans. T. Watkins (Cambridge University Press, 2000). 
to the transformation was the development of symbolic imagination and a mythical interpretation of the natural world. In other words, religion was not an after-effect of changes in managing the material world (as in some Marxist hypotheses), but ingredient to the transformation of the human mind that made the Neolithic revolution possible. To put it bluntly, in some sense "religion" was a causal factor in the rise of domestication and sedentism, or at least, as Ian Hodder would put it, "entangled" within the rise of these developments.

Despite his provocative title, which fits nicely with the metaphor guiding the reflections of this chapter, Cauvin's analysis does not really deal with the origin of the gods per se, but with the emergence of symbolic and mythical interpretations of the world. I agree that religion played a creative role in this revolution, but want to suggest that closer attention to the actual mechanisms by which supernatural agents are born(e) can complement these broader reflections. Given my interest in the fertility of the mental and social fields of Çatalhöyük during the Neolithic, one might expect me to focus on the wellknown imagery of the "goddess" so often associated with that site. Unlike Cauvin, however, I do not find the "Goddess and Bull" mythology inspired by Mellaart's earlier interpretations compelling.

As Hodder and Meskell argue, it seems more likely that Çatalhöyük was characterized more by the kind of phallocentrism typical of other sites in the region such as Gobekli Tepe. ${ }^{6}$ My interest is not primarily in the perceived sexual antics performed - or the alleged reproductive assistance provided - by any female or male divinities in the mythological "spirit world" of Çatalhöyük, but in the mechanisms by which the god(desse)s themselves were born(e) within the embodied and encultured cognition of its inhabitants. Moreover, that interest itself is driven not only by a fascination with the original revolutionaries of the Neolithic but also with the current "inhabitants" of Çatalhöyük, that is, the interdisciplinary and international team of researchers who ritually descend upon it every summer.

Unlike those whose bones, belongings, and abodes they study, for the most part these scientists are anthropomorphically prudish (suspicious of causal explanations that appeal to supernatural agents) and sociographically promiscuous (seeking out the insights of other disciplinary coalitions). In the conclusion of this chapter I will return to the conceptual apparatus of Figure 1 and examine the tension this creates among the various shareholders interested in the revelations of those who dig the site Now. In the next three sections,

6 Hodder and Meskell, "The Symbolism of Çatalhoyuk in Its Regional Context," in Religion in the Emergence of Civilization: Catalhoyuk as a Case Study, ed. Hodder (New York: Cambridge University Press, 2010). 
however, my focus will be on the current team's research questions related to power, production, and property in Çatalhöyük during the Neolithic, exploring the extent to which these dynamics may have been entangled with the theogonic mechanisms outlined briefly above.

\section{Burials, Bulls, and Proprietary Production}

Perhaps there were no "goddesses" at Çatalhöyük, but there is strong evidence in the data that supports the claim that its original inhabitants engaged in behaviors intended to engage supernatural agents whom they considered to be socially and causally relevant to their coalition. In his analysis of the site in The Leopard's Tale, Ian Hodder suggests that "as people, society and crafted materials increasingly became entangled and codependent, so the codependent material agents were further enlisted and engaged in a social world in which spirits were involved." $\mathrm{He}$ also explicitly proposes a link between "control of knowledge about and the objects of the spirit world" and the acquisition and maintenance of rights, resources, status and prestige in the community (250). In this context, I take terms like "spirits" and "spirit world" to be roughly synonymous with what I have been calling supernatural agents and coalitions.

My concern is with the role played by theogonic mechanisms in this entanglement. We could point to many instances of material objects that indicate shared imaginative engagement with "gods" in the broadest sense. For example, the polishing and caching of obsidian mirrors may have been conceived as a way of seeing or divining the "spirit world" (229, 239). More speculatively, one might argue that the making of figurines could be an expression of a growing awareness of and interest in detecting or even controlling human-like agents, i.e., anthropomorphic promiscuity. Moreover, the repetitive patterns of architecture and art within houses and across levels suggest a rather prudish sociography. At any rate, I want to focus here on the two types of supernatural agents that seem particularly prevalent within the socius: aurochs and ancestors.

I see dead people. But like most of my cosmopolitan colleagues, I see them rarely, briefly, mostly at funerals, usually once, and only one at a time. The original inhabitants of Çatalhöyük, on the other hand, saw dead people much more often. Indeed, one of the most distinctive features of the "town" is the burial of some of the dead within the houses, often immediately under the

7 Hodder, Catalhöyük: The Leopard's Tale - Revealing the Mysteries of Turkey's Ancient "Town" (New York: Thames \& Hudson, 2006), 195. Unless otherwise noted, page numbers in the following paragraphs refer to this book. 
main sleeping area. It is hard to know whether this was comforting or as creepy to them as it is to us. Whatever the case, the removal, burial, and long-term retrieval of skulls as well as other forms of treating the skeletons indicates that their manipulation was perceived as an engagement with supernatural agents whom they imagined played some sort of causal role in the coalition. But human ancestors were not the only, and perhaps not even the most important, disembodied intentional entities by which the thoughts and actions of their daily lives were herded.

Holy cow. What is one to make of all the bull at Çatalhöyük? There are many types of dangerous animals represented in the painting and decoration of the houses, including bears and leopards. However, bulls (aurochs) seem to have played a particularly significant role. It would be anachronistic to call them "sacred" cows, but it appears that the aurochs were indeed set apart as dominant agents within the shared imagination of the coalition. Their buchrania in particular were a prominent part of the décor. Moreover, their positioning sometimes suggests that they bear some relevant relation to the human burials within the homes. We will return below to the possible connection between aurochs and ancestors within what Ian Hodder calls the "prowess-animal spirit-hunting-feasting" nexus that seems so important in life at Çatalhöyük.

At this point I want to emphasize two things. First, as Hodder points out, both of these types of disembodied agents within the spirit world appear to have played a special role in mediating power related to proprietary production, i.e., in providing access to the fruit of communal labor. He hypothesizes that the power of dominant groups such as elders or shamans may have been based partly on their capacity to intercede in relation to wild animals and ancestors (204). There may have been competition between forms of power based on the control of knowledge about ancestral ties and auroch behavior and forms of power based on domestic production and accumulation, but Hodder suggests all of these dimensions (material, social, spiritual) were entangled and mutually conditioned one another. "It seems most likely that much of the variation in elaboration of buildings, and in the number of burials, relates to the ability of household members (perhaps especially elders) to mobilize ritual, symbolism, revelation and their performance, even though exchange and production played their part" (183).

Second, the remains of both ancestors and aurochs played a special role in the ongoing process of hiding and revealing that characterized so much of the ritual behavior at Çatalhöyük. The sharp parts of animals (including bulls) were placed in walls, covered and uncovered over and over again. Human skulls (as well as sculptures and other artifacts) were buried, dug up, kept over time, and re-buried. Hodder proposes that this process of material circulation 
played a role in maintaining social continuity within the houses and had some bearing on status and power. "Things are hidden and then revealed. And often they are hidden in places where the ancestors and animal spirits are - beneath floors and behind walls. So when things return, revealed, they bring with them an aura from that other world. They have been magnified in their hidden journey" (170, emphasis added). These repetitive and apparently ritual (un)covering processes appear to be linked to both ancestry and exchange.

In what follows I hope to contribute to the ongoing unearthing of the mysteries of the Çatalhöyük community by exploring ways in which our current knowledge of the naturally evolved human tendencies toward anthropomorphic promiscuity and sociographic prudery, which together help to explain why and how gods are born(e) in the mental and social space of human life, could lead to new hypotheses about the role of supernatural agents within their daily lives in general and proprietary production in particular. Both dead ancestors and aurochs clearly qualify as supernatural agents, in the sense defined above. The way in which their remains were engaged indicates shared beliefs about the causal power and intentionality of these disembodied entities within the coalition. What role did the integration of theogonic mechanisms play at Çatalhöyük?

\section{Anthropomorphic Promiscuity at Çatalhöyük}

As we have seen, there is a massive and rapidly growing literature supporting the claim that most human beings have a naturally evolved tendency to overdetect agency, intentionality, and purposiveness. Neurological, psychological, and ethnographic research across cultures has demonstrated that human cognition somewhat automatically seeks out (more or less human-like) agents. Even the random movement of dots on a computer screen can easily be interpreted as "intentional" and, especially under stress, most subjects will immediately guess "agent" with little or no priming when confronted with this sort of ambiguous phenomena. Humans seem to have evolved with a "hairtriggered" cognitive mechanism for detecting agents.

Stewart Guthrie's 1993 book Faces in the Clouds is still the best place to start for an introduction to the issue of anthropomorphism. Although a great deal of scientific research in the intervening decades has clarified the cognitive and cultural mechanisms involved, Guthrie's book provides a clear exposition of its prevalence and a daring philosophical assessment of its importance. His cognitive theory of religion is built on the reasonable hypothesis that the survival of early humans depended on their ability to perceive any other 
agents - especially other people - who might be around. ${ }^{8}$ Hypersensitivity to human-like agents leads to many false alarms (e.g., seeing faces in the clouds) but it also makes it more likely that hidden agents will be perceived when it is really important (e.g., a camouflaged enemy). For Guthrie, anthropomorphism is by definition the failure of a naturally evolved perceptual strategy, and religion is systematized anthropomorphism.

Religious anthropomorphism is often understood as consisting of the attribution of humanity to gods, but Guthrie turns this around: "gods consist of attributing humanity to the world." In this sense all religions have gods or a god; they all involve "ostensible communication with humanlike, yet nonhuman, beings through some form of symbolic action."10 The example of Buddhism is often raised as a counterexample, but although some philosophical streams of that tradition resist anthropomorphism (as do minority streams within all the axial age traditions), the vast majority of Buddhists are deeply entangled in shared imaginative engagement with all kinds of supernatural agents such as devas, bodhisattvas and, of course, Buddhas. The question before us is what communication with "gods" such as the spirits of aurochs and ancestors may have looked like at Çatalhöyük.

To my knowledge the most explicit application of the research on (what I am calling) anthropomorphic promiscuity to Çatalhöyük is in the work of David Lewis-Williams and David Pearce. ${ }^{11}$ As we noted in Chapter 2, these authors emphasize the neurological basis of belief in supernatural agents, which they interpret as the result of mistakenly attributing reality to iconic hallucinations experienced during altered states of consciousness. Based on neurological studies and ethnographic work in many contemporary small-scale societies, they argue that religion evolved as those who were particularly susceptible to or adept at having such experiences (shamans) came to be understood as capable of mediating between the human coalition and the spirit world.

Building on Lewis-Williams' earlier analysis of upper Paleolithic cave art, ${ }^{12}$ they argue that the similarity between images found in the latter, such as handprints and geometric designs reminiscent of entopic phenomena in altered states, and the images found at Çatalhöyük suggest that the houses were a "built cosmos" replacing caves as the axis mundi within which mediation with spirit

\footnotetext{
8 Guthrie., "A Cognitive Theory of Religion [and Comments and Reply]," Current Anthropology (1980).

9 Guthrie, Faces in the Clouds, 3-4.

$10 \quad$ Ibid., 197.

11 Lewis-Williams and Pearce, Inside the Neolithic Mind.

12 Lewis-Williams, The Mind in the Cave.
} 
worlds can occur. Long before sedentism, human groups were participating in shared engagement with supernatural agents, especially human-animal hybrids perceived during hypnagogic states as hovering above or emerging from other worlds below. "The domestication of animals was already conceptually embedded in the worldview and socio-ritual complex we have described before people began actually herding the aurochs." ${ }^{13}$ Here we have another example of the claim noted above, defended in different ways by Cauvin and Hodder, that symbolic imaginative engagement with "spirits" contributed to the revolution(s) of the Neolithic.

This interpretation of Çatalhöyük, whatever its other weaknesses or strengths, does not adequately incorporate some of the other popular hypotheses surrounding the phenomena of anthropomorphic promiscuity. Without downplaying the neurological basis of the over-active perception of agency, we should also note that one of the most important reasons for the hypersensitivity of this cognitive mechanism is the adaptive value of quickly detecting predators and prey. The predominance of dangerous animals in the art and décor of Çatalhöyük, including reliefs of leopards and bears as well as the teasing and hunting of bulls, suggests that they were particularly interested in perceptual strategies related to these agents.

It makes sense, then, that the spirits of powerful predators would have been attributed power in the spirit world as well, and that the inhabitants of Çatalhöyük would have been primed to detect them. Whatever the details, we can plausibly conclude that their evolved hypersensitivity to seeking out agents was operative in their growing attempts to find, control, respond to, and manipulate dangerous agents even (or especially) in the spirit world. Shared engagement with such imagined agents may well have led to new strategies for finding and controlling actual agents in the natural environment and contributed to domestication and sedentism.

But of course predators and prey are not the only agents that are important to detect; for the species to survive, humans also need to find protectors and partners. Here is where the ancestors come in. Homo sapiens in the Neolithic, like their forebears and descendants, were born with a tendency to seek out protectors (usually parents) and developed an interest in seeking out partners (potential sexual mates). Our attachment to these embodied human agents does not suddenly disappear when they are not around; even after their death we feel emotionally connected to them. The powerful cognitive mechanics of anthropomorphic promiscuity continue to grind away and, given the significance of our attachment to such care-giving figures within the working models

13 Lewis-Williams and Pearce, Inside the Neolithic Mind, 141. 
by which we navigate life, it is easy to understand why we remain predisposed to perceive their presence.

In the "attachment theory" developed by John Bowlby and others, ${ }^{14}$ the dynamics of the human behavioral system are described in explicitly evolutionary terms. Systems in which infants actively sought attachment with care-givers, and care-givers quickly detected and responded to the needs of infants, were naturally selected, and such dispositions became stronger over time. More recently, researchers have demonstrated that the attachment styles developed in infancy and childhood continue to affect adult life, especially in close and romantic relationships. ${ }^{15}$ Moreover, this deeply embedded drive for attachment also shapes people's relation to their perceived divine attachment figures, at least in the case of images of "God."16

In other words, our naturally evolved hyperactive longing for attachment with embodied human agents easily spills over into a promiscuous seeking for and imaginative engagement with supernatural partners and protectors. Of course gods are not always (or even usually) nice and supernatural agent coalitions are just as (if not more) likely to include fearsome predators as they are potential caregivers. For our purposes, however, the main point is that the data at Çatalhöyük can be illuminated in light of such theories. In my view, the most compelling example is the well-known case of the skeleton of a woman buried embracing a plastered skull. However, we could also point to the burials of infants, figurines or even animals as examples of evidence that our Neolithic ancestors continued to detect the presence of their own dead ancestors (and others) with whom they had developed significant attachments.

We should be suspicious, as always, of overly speculative interpretations of the archaeological evidence, but if the inhabitants of Çatalhöyük were anatomically modern humans with the same basic cognitive mechanisms that we have today, we have good reasons to suspect that the data is at least susceptible to such explanations. However, this is not the whole story. Supernatural agents may be born through overly-sensitive cognitive mechanisms for detecting relevant intentional forces but this does not explain why human families

\footnotetext{
14 Bowlby, Attachment (New York: Basic Books, 2008), John Bowlby, A Secure Base: Clinical Applications of Attachment Theory (London: Taylor \& Francis, 2005).

15 See, e.g., Mikulincer, Attachment in Adulthood: Structure, Dynamics, and Change (Guilford Publications, 2007); Rholes and Simpson, eds., Adult Attachment: Theory, Research, and Clinical Implications, (New York: The Guilford Press, 2004).

16 Kirkpatrick, Attachment, Evolution, and the Psychology of Religion (New York: The Guilford Press, 2004).
} 
continue to bear responsibility for taking care for them. It takes the overlysensitive protection of a village to raise a god. Or, in the case of Çatalhöyük it took a Neolithic "town."

\section{Sociographic Prudery at Çatalhöyük}

The claim that religion plays a role in holding together human groups is hardly new. In fact, for much of the 2oth century theories (like Durkheim's) that posited a social function at the root of religion were more influential than views (like Tylor's) that posited belief in "spiritual beings" as its essential characteristic. In the last few decades, however, empirical findings and theoretical reflection across the disciplines that study religion have contributed to an integration of these intuitions. The cognitive mechanisms that give rise to belief in supernatural agents and the coalitional mechanisms that hold groups together are mutually reinforcing. While one finds a natural and healthy competition among scientific hypotheses on these topics, they are for the most part complementary and even convergent.

But how have these developments affected the interpretation of Çatalhöyük? Lewis-Williams and Pearce have proposed that shamans played a key role in regulating the "social contract" of its inhabitants as a way of dealing with their shared interpretations of the introverted end of the consciousness spectrum. ${ }^{17}$ In other words, like all societies, they had to develop a "consciousness contract" as a way of dealing with their experiences of altered states of consciousness. The presence of entopic patterns and other representations in the art and architecture of Çatalhöyük that are reminiscent of shamanic cultures suggests to Lewis-Williams and Pearce that their social organization was structurally similar to that of others across the world. However plausible this may be, it does not go very far in explaining the actual mechanisms that produced and maintained the sociographic prudery of this particular Neolithic town.

Whitehouse and Hodder have pressed further by applying Whitehouse's "modes of religiosity" theory to Çatalhöyük. ${ }^{18}$ They point to evidence that suggests a slow shift from primarily "imagistic" toward more "doctrinal" modes

\footnotetext{
17 Lewis-Williams and Pearce, Inside the Neolithic Mind.

18 For an introduction to this theory, see Whitehouse, Modes of Religiosity: A Cognitive Theory of Religious Transmission (Walnut Creek, CA: AltaMira Press, 2004), and Whitehouse and McCauley, eds., Mind and Religion: Psychological and Cognitive Foundations of Religion (Walnut Creek, CA: AltaMira Press, 2005).
} 
of transmission during the 1,600 year settlement. ${ }^{19}$ The former mode is characterized, among other things, by emotionally intense rituals with low frequency, while the latter mode involves more frequent but less intense rituals. They take the transition from extensive use of buchrania in the lower levels to a growing presence of stamp seals and pictorial narratives in the upper levels to indicate that the coalition became increasingly "doctrinal" over the centuries.

They also suggest that as shamans (loosely defined) came to develop discursive and narrative strategies for transmission the settlement became characterized by more standardized ways of engaging and more authoritative interpretations of the spirit world. This highlights the importance of Çatalhöyük as a transitional site, which may have "paved the way for more centralized, large-scale and hierarchical patterns of political association." 20 One of the values of this theory is the way in which it illuminates the link between cognitive and coalitional structures at Çatalhöyük. The social morphology of the town became more complex as a result of the relation between divergent modalities of ritual transmission. Examining the archaeological data in this light will likely lead to new insights about the impetus for such change, identifying patterns that would otherwise have been missed.

It seems to me that there are at least two other types of theories related to sociographic prudery that could complement this proposal and lead to additional insights about the actual mechanisms at work at Çatalhöyük. The first type has to do with the role of supernatural agents in moral evolution. ${ }^{21}$ If organisms survive by taking care of themselves, why do we find apparently altruistic behavior in human life, such as actions in which an individual sacrifices her needs for the group? Some of the most popular scientific answers to this question these days are variants of the claim that the imagined presence of "gods" helped to solve the problem of cooperation within coalitions. It is often in the best interest of an individual to defect or cheat, especially if they can do so without being caught. However, if one is convinced that supernatural agents, who have fuller access to knowledge about socially relevant human actions and the power to bring or hinder misfortune, may be (or always are) watching, one is more likely to follow the rules that hold the group together.

19 Whitehouse and Hodder, "Modes of Religiosity at Çatalhöyük," in Religion in the Emergence of Civilization: Çatalhöyük as a Case Study ed. Hodder (Cambridge: Cambridge University Press, 2010).

$20 \quad$ Ibid., 142.

21 See, e.g., Hauser, Moral Minds: The Nature of Right and Wrong, (New York, NY: Harper Perennial, 2007), and Pyysiäinen and Hauser, "The Origins of Religion." Trends in Cognitive Sciences 14, no. 3 (2010). 
To my knowledge, such hypotheses have not been extensively applied to the Çatalhöyük material. This may be due in part to the fact that so little is known (or knowable) about the ethical codes or norms that guided their daily lives. Nevertheless, we do know that once supernatural agents have emerged within the human imagination, they are automatically attributed qualities that are common to the category Person, such as thoughts, intentions and desires. We also know that the way in which they minimally violate intuitions about this category, such as embodiment, actually makes them easier to remember, which is why ideas of gods are such socially contagious concepts. Given our shared phylogenetic heritage, which includes such cognitive tendencies, it is reasonable to postulate that shared belief in "spirits" played a similar role in enhancing cooperation among the inhabitants of this Neolithic community. Like all other groups of Homo sapiens, the members of the Çatalhöyük coalition would have naturally and automatically wondered what their supernatural agents thought or desired.

What do goddesses want? For that matter, what did any of the gods of Çatalhöyük - animal spirits or deceased ancestors of either gender - want? At least during the period of the lower levels, the inhabitants of the houses would have been constantly confronted with images of buchrania (and other symbols) that would have activated the idea that animal spirits were watching them. Repeated burials and re-burials within the houses would also have reinforced a sense that their ancestors may be listening. What are the animal spirits thinking about what they see? What are the ancestors feeling about what they hear? Whatever the specific answers, it is plausible to assume that this general sort of question had the effect of solidifying a willingness to cooperate in the ongoing rituals and moral conventions of Çatalhöyük. The ambiguity produced by the repeated hiding and revealing of bones and other artifacts would only have reinforced the mechanisms of religious reproduction.

A second set of promising hypotheses, linked to what I have called sociographic prudery, that have not (to my knowledge) been applied to Çatalhöyük are those related to costly signaling theory. Here too the issue is explaining what appear to be anomalies within evolution, such as extravagant peacock tails, which require a high percentage of metabolic energy and weaken the capacity to evade predators. Such tails, however, are a signal to peahens that their carrier has genes strong enough to survive. In the case of religion, the phenomena to be explained include behaviors that are costly in terms of time and energy, often painful and also without any clear survival value. Richard Sosis, for example, points to the rituals of the Ilahita Arapesh, in which adult males dressed like boars pin down three year old boys and rub their genitals 
forcefully with stinging nettles. ${ }^{22}$ The descriptions of the molestations that must be suffered by males in this coalition, which continue in various forms throughout their lives, would make Hesiod blush.

Sosis argues that these and other religious behaviors, including the pursuit of badges and the acceptance of bans, neither of which provide (but often reduce) adaptive advantage, are actually forms of costly signaling. Participation signals commitment to the group, which strengthens the solidarity of the coalition and indirectly benefits the survival of the gene pool. For the most part, and over the long run, the most convincing displays are by those who are really committed to their beliefs and their promises to the coalition. People whose beliefs are internalized are willing to engage in displays of commitment that are (otherwise) so unreasonable that they would be very hard to fake. To cite Atran again: "collective commitment to the absurd is the greatest demonstration of group love that humans have devised."23 The most reliable signals of this love, which protects the coalition by reinforcing the willingness of its members to cooperate, coordinate, and compete are by those who truly believe that they are in coalition with supernatural agents.

How might this apply to Çatalhöyük? There is no strong evidence of excessively violent rituals, but the art depicts the teasing of wild animals, which appears dangerous indeed. Moreover, there does not seem to be any survival advantage in having extremely sharp bulls' horns protruding from the inner walls of one's house. Using cognitive energy to remember how deeply an ancestor is buried, and physical energy to dig them up and rebury them, have no obvious adaptive value. Given the explanatory power of costly signaling theory in so many other contexts, when we dig up something that indicates a widespread form of behavior that does not enhance fitness it seems reasonable to ask whether we have found evidence for shared imaginative engagement with supernatural agents. Participating in the various frequent rituals within the houses, as well as the less frequent rituals connected with hunting, baiting, and feasting on bulls, would have been way of signaling commitment to coalition members, including those in the spirit world. This in turn would have strengthened the cohesion of the Çatalhöyük community.

Unfortunately, the other side of in-group cohesion is often out-group antagonism. Especially under difficult conditions, commitment to one's own group can reinforce discrimination against other groups. This is a natural evolutionary mechanism but, as John Teehan points out, religion can intensify

\footnotetext{
22 Sosis, "Religious Behaviors, Badges, and Bans," 61.

23 Atran, Talking to the Enemy, 450. See also Bulbulia, "Religious Costs as Adaptations That Signal Altruistic Intention," Evolution and Cognition 10, no. 1 (2004).
} 
this discrimination by giving the moral differentiation between groups a divine sanction and raising the stakes of commitment to cosmic proportions. ${ }^{24}$ Teehan's analysis focuses on the Abrahamic religions, demonstrating how the ethical codes of these monotheistic traditions are expressions and extensions of, rather than exceptions to, the natural moral intuitions that emerged through the evolution of human brains in social groups.

The people of Çatalhöyük were clearly not monotheists, and there is not yet any clear evidence of violence toward in-group defectors or out-groups. This lack of evidence is itself one of the most fascinating features of the site, and its further exploration may shed light on the conditions that give rise to religious (or other) violence. In the meantime, there is much to ponder about our own propensity toward anthropomorphic promiscuity and sociographic prudery, which, on this side of the rise of the axial age religions and in this ever more complex space of global pluralism, may no longer have adaptive value for the human race. Seeking out and protecting supernatural agent coalitions with dead ancestors and aurochs may have helped keep the inhabitants of Çatalhöyük alive by providing a kind of emotional and social entangling force that held together their modes of proprietary production. But following similar strategies today could end up killing us.

\section{Theolytic Mechanisms in Science and Theology}

Digging at Çatalhöyük has revealed a great deal about the complex revolutionary changes that occurred in the evolution of humanity during the Neolithic. But can its physical and conceptual excavation disclose anything important about the difficult task our species faces today in learning to adapt to ever more complex intellectual and social challenges? If placed within the broader context of the phylogenetic emergence and psychological and political effects of god-bearing mechanisms I believe it can. In this context I only have space for a few provocative suggestions.

As I indicated above, my primary interest is in how insights into the lives of the Neolithic inhabitants of Çatalhöyük can help us understand ourselves as we struggle to understand them. We too are entangled in particular ways of tending to proprietary production, but most of us live a quasi- or post-sedentary life in which not just plants and animals but the natural environment itself is largely domesticated. We have become digital nomads, information huntergatherers roaming around a virtual global socius. The cognitive and coalitional

24 Teehan, In the Name of God, 174. 
tools that we still use in our navigation of this world, however, evolved in an environment with very different natural and social challenges. Tendencies toward anthropomorphic promiscuity and sociographic prudery served (some of) our ancestors well - but how are they working out for us?

Earlier I alluded briefly to the fact that scientists tend to be anthropomorphically prudish and sociographically promiscuous; let me now explain what I mean. Most scientists resist explanations of phenomena that appeal to the causal influence of disembodied intentional agents like the spirits of animals or ancestors. Regardless of academic discipline, such ideas are not welcome in the logical chains of their arguments or in the planning of their empirical experiments.

For example, one will not find in archeological journals any explanations of the data at Çatalhöyük that appeal to the actual causal efficacy of bull spirits (or goddesses) within the coalition. Most archaeologists would also be suspicious of any claims from their colleagues that their knowledge about the site had been revealed to them through angels or astrology. "The religious world increases the number and influence of intentional agents while science ultimately aims to minimize both by seeking alternative accounts of affairs in terms of underlying, predictable, non-intentional mechanisms." ${ }^{25}$ In other words, scientists are (or try to be) anthropomorphic prudes.

Scientists are also suspicious of claims that appeal primarily or solely to authority or convention. Certainly they operate within a particular disciplinary tradition, and must take much of what is handed down to them in trust, but scientists raise their eyebrows when a particular argument is immunized from critique because of the reputation of its source or the longevity of its popularity. For example, for many years the consensus of the archeological community was that early hominin groups were violent. For the members of the Hodder team with whom I have interacted, actively seeking out new ways to organize the inquiry of their disciplinary socius in light of the new data at Çatalhöyük is more important than fidelity to such dominant conventions. Like most scientists, they pursue novel ways of inscribing the academic field with new hypotheses. In the case of the current (summer) inhabitants of Çatalhöyük, this also involves openness to intercourse with other disciplines - even philosophy and theology.

We can think of these two reciprocally reinforcing tendencies among scientists as theolytic mechanisms because of the way in which they loosen or dissolve (lysis) the hold of supernatural agents or gods (theōn) on human minds

25 Lawson and McCauley, Rethinking Religion: Connecting Cognition and Culture (Cambridge: Cambridge University Press, 1993), 162. 
and coalitions. The relationship between these mechanisms are depicted in Figure 2 (see Chapter 1, p. 64). We do not have space here to deal with the other two (upper left and lower right) quadrants of this diagram, which represent quite different ways of integrating the mechanisms; suffice it to say, they lead to approaches that are either too prodigal or too penurious to work. ${ }^{26}$ For our purposes here, the important point is the diametrical opposition between the direction sponsored by theogonic mechanisms (in the lower left quadrant) and the direction represented in the upper right quadrant of Figure 2.

The integration of theolytic mechanisms unveils the hidden mechanisms by which supernatural agent coalitions are born(e). My rhetorical use of the phrase "unveiling theogonic mechanisms" is inspired by Rene Girard's wellknown concept of the scapegoat mechanism. ${ }^{27}$ One might argue that the scapegoat mechanism is simply one (important) example of the integration of theogonic mechanisms, insofar as the former involves the detection of an ambiguous intentional force that must be dealt with in order to maintain the social cohesion of and psychological stability of an in-group. In this context, however, it is important to note some similarities and differences between scapegoating and the integrated theogonic mechanisms we have been discussing. Here is perhaps the basic difference:

- The scapegoat mechanism creates weak victims, more or less vulnerable, who must be cursed, sent away, or destroyed in order to rid the community of violence, sin or evil.

- The theogonic mechanisms, on the other hand, create powerful perpetrators, more or less in-vulnerable, who must be appeased in some way, in order to avoid misfortune or acquire blessing.

Both theogonic and scapegoating mechanisms "work," in the sense that persons within the in-group often feel better and their communities often survive longer because of them. One of the basic similarities between these mechanisms is that their "working" can actually make things worse.

- Removing or destroying scapegoats reinforces the powerful belief that our problems can be solved by more violence.

26 I discuss these two quadrants in Chapter 7 below ("Theology After Pandora"), and in Chapter 6 of Shults, Theology after the Birth of God: Atheist Conceptions in Cognition and Culture (Palgrave Macmillan, 2014).

27 Girard, Violence and the Sacred (Johns Hopkins University Press, 1977); Girard, The Scapegoat, (Baltimore: Johns Hopkins University Press, 1986). 
- Detecting and protecting gods reinforces the powerful belief that our problems can be solved by our coalition with supernatural agents.

Another important similarity is that the very process of unveiling any of these mechanisms weakens their power. This is because they only work well when they are hidden to those within whom or upon whom they are operating.

When we begin to recognize what we are doing to scapegoats, and what our scapegoating is doing to us, the process no longer automatically has the effect of (temporarily) calming us psychologically and politically. Similarly, as we begin to see how gods are born(e) in human cognition and culture, such conceptions can more easily become the objects of our critical reflection rather than surreptitiously shaping our subjectivity. For the reasons outlined in previous sections, evolution has predisposed many of us to think, act, and feel in ways that keep these mechanisms hidden.

This is why exposing the reproductive processes of god-bearing can be so difficult and even frightening. We have evolved not to challenge beliefs in the things hidden in the walls and foundations of our coalitions. Challenging the beliefs or practices related to the supernatural agents of other traditions easily leads to conflicts that can quickly escalate and become dangerous. And so we avoid this too. This may not have been much of an issue at Çatalhöyük, with a relatively small and homogenous population. There would be no reason to challenge the efficacy of engaging the spirit world by hiding and revealing skulls, the sharp parts of animals, and other artifacts. During the Neolithic, the ambiguity and mystery surrounding these processes would only have further activated the natural tendencies to detect human-like agency and to protect one's place in the collective by costly signaling of commitment.

Now, however, we face very different adaptive challenges in an increasingly pluralistic and interconnected global environment, in which we rely ever more deeply and are affected ever more intensely by scientific modes of inquiry and technological developments. During times of crisis, the same theogonic mechanisms that produce and maintain the supernatural agent coalition of a particular in-group also intensify it's members' anxiety about and discrimination toward out-groups. Allowing these procreative urges to run wild in our current context is no longer productive. We can no longer afford to romanticize the human search for gods to protect and partner with us; it may once have been a harmless (or even helpful) romantic distraction, but today it is distracting us from the urgent task of developing new strategies for surviving in a rapidly changing environment.

Facilitating and strengthening theolytic mechanisms will not be easy. It will require great psychological and political sensitivity in relation to a wide array of stakeholders, including not only scientists from diverse disciplines, but also 
laypeople and leaders associated with religious institutions, museums, educational groups and funding agencies. Nevertheless, it is important to realize that, whether or not we mean it to, digging up Çatalhöyük has a theolytic effect. In my view it is best not to hide these mechanisms; we should bring them out in the open for analysis and evaluation. Engaging in anthropomorphically prudish and sociographically promiscuous reflection on the processes by which gods are born(e) increases our capacity for adapting intentionally. Although this is not the job of archaeologists, anthropologists, or psychologists qua scientists, the kind of space created by international and interdisciplinary projects like the one at Çatalhöyük provide an excellent opportunity for such intentional dialogue.

But what role could theology possible play in this endeavor? The vast majority of theologians have operated within the context of one of the religious traditions that can trace its roots to the axial age; for the most part, they have reinforced the detection and protection of particular supernatural agent coalitions. This direction within theology, which I call its sacerdotal trajectory, has by far been the most dominant and obviously contributes to theogonic reproduction. However, there have always been streams of dissent within these traditions, forces that push against anthropomorphic conceptions of the divine and push toward modes of sociography that do not inscribe harsh boundaries between groups. Pressing in this direction, which I call the iconoclastic trajectory of theology, has the effect of breaking the power of particular images of gods whose detection protects a conventional way of inscribing the socius. ${ }^{28}$

Theologians (or a-theologians) who follow this latter course today are in a unique position to collaborate with scientists in the unveiling of theogonic mechanisms. For example, demonstrating the logical incoherence of the notion of an infinite Supernatural Person, for which there are a wealth of resources even within the monotheistic traditions, can complement scientific challenges to the plausibility of appeals to the intervention of finite supernatural agents in the natural world. ${ }^{29}$ In Chapter 5 below I will argue that the best strategy here is not to attempt to disprove the possibility or even to weaken the probability of such causation through deductive or inductive arguments, but to challenge the plausibility of such religious hypotheses by offering abductive arguments that more adequately explain the phenomena without appealing to

28 This is discussed in more detail in Chapters 6 and 7 below, and in Shults, Theology after the Birth of God.

29 For a fuller argument for this claim, see Shults, "Science and Religious Supremacy: Toward a Naturalist Theology of Religions," and Shults, Iconoclastic Theology. 
hidden revelations, thereby making it easier to disentangle the gods from the material and social dimensions of our proprietary production.

To an extent hardly imaginable even a century ago, we have gained significant control over the processes of childbirth. Developing effective means of divine birth control may prove to be much more difficult. It may turn out to be impossible. Perhaps theogonic mechanisms are so deeply embedded in our phylogeny that we can never escape the ontogenetic delivery of the gods. If so, the supernatural population will continue to grow within the natural mental and social space of Homo sapiens. The planet already feels overcrowded physically, emotionally, cognitively.

Given the potentially destructive effects of psychological strategies that are based on detecting divine attachment figures and political strategies that are driven by protecting supernatural coalitions, it seems to me that we can no longer avoid the challenge all parents must face. Some ways of caring for our offspring can become addictive and unhealthy; holding on to them too long is not good for us. Can we learn to let go of our supernatural progeny? It may become easier as the processes behind their mysterious arrival within our families of religious origin are increasingly unveiled. 